\title{
Prognostic value of CIP2A gene expression in adult Egyptian acute myeloid leukemia patients
}

\author{
Roxan E. Shafik', Azza M. Ibrahim², Fadwa Said ${ }^{2 *}$, Naglaa M. Hassan' ${ }^{1}$, Hanan E. Shafik ${ }^{3}$ and Hala A. Shokralla ${ }^{3}$
}

\begin{abstract}
Background: Protein phosphatase 2A (PP2A) functions as a tumor suppressor in many cancers. Cancerous inhibitor of protein phosphatase 2A (CIP2A) inhibits PP2A proteolytic degradation of C-Myc and enhances cell growth and tumor formation in several tissues. CIP2A expression in acute myeloid leukemia (AML) and its effect on outcome of treatment were not reported in Egyptian patients.

Results: No significant difference was detected in CIP2A expression between AML and control groups ( $P=0.48$ ). However, in AML patients, those with low CIP2A expression had a longer median overall survival than those with high expression $(P=0.059)$. CIP2A expression was not related to the clinical and laboratory variables and did not affect response to treatment.

Conclusion: High-CIP2A expression was associated with a trend of shorter overall survival in adult Egyptian AML patients. It might serve as a useful marker to predict poor prognosis. CIP2A may represent a potential target for cancer therapy.
\end{abstract}

Keywords: AML, CIP2A, RT-qPCR

\section{Background}

Acute myeloid leukemia (AML) encompasses a heterogeneous group of biologically and clinically aggressive disorders that result from genetic and epigenetic changes in hematopoietic progenitors. Despite considerable advances in the understanding of the biology of AML, overall survival (OS) remains poor because of the high rate of relapse after achievement of complete remission (CR) and failure of primary induction chemotherapy $[1,2]$.

Patients with cytogenetically normal AML (CN-AML) are usually classified in the intermediate-risk prognostic category because their CR rate, relapse risk, and survival are worse in comparison to patients with favorable aberrations such as $t(8 ; 21)$, $\operatorname{inv}(16) / t(16 ; 16)$, or $t(15 ; 17)$. However, performance of CN-AML is better than

\footnotetext{
* Correspondence: f2said@yahoo.com

${ }^{2}$ Clinical Pathology Department, Cairo University, Cairo, Egypt

Full list of author information is available at the end of the article
}

patients with unfavorable cytogenetic findings such as monosomy 7 , inv( $3 ; 3)$, balanced translocations involving $11 \mathrm{q} 23$ other than $\mathrm{t}(9 ; 11)$, or complex karyotype [3, 4]. Of note, the outcomes of therapeutic approaches differ among patients with CN-AML probably because this cytogenetic subset is heterogeneous at the molecular level. Numerous mutations and changes in gene expression that affect clinical outcomes have been discovered in CN-AML patients [5-9].

Protein phosphatase 2A (PP2A) is a major serine/ threonine phosphatase that functions as a tumor suppressor in several cancers. It negatively regulates numerous signal-transduction pathways [10-12]. Cancerous inhibitor of protein phosphatase $2 \mathrm{~A}(C I P 2 A)$ is an endogenous protein that interacts with both $P P 2 A$ and the oncogenic transcription factor $c-M y c$. CIP2A inhibits dephosphorylation of $c-M y c$ serine 62 by $P P 2 A$, leading to prevention of proteolytic degradation of $c-M y c$. CIP2A activity enhances anchorage-independent cell growth

\section{Springer Open}

(c) The Author(s). 2020 Open Access This article is licensed under a Creative Commons Attribution 4.0 International License, which permits use, sharing, adaptation, distribution and reproduction in any medium or format, as long as you give appropriate credit to the original author(s) and the source, provide a link to the Creative Commons licence, and indicate if changes were made. The images or other third party material in this article are included in the article's Creative Commons licence, unless indicated otherwise in a credit line to the material. If material is not included in the article's Creative Commons licence and your intended use is not permitted by statutory regulation or exceeds the permitted use, you will need to obtain permission directly from the copyright holder. To view a copy of this licence, visit http://creativecommons.org/licenses/by/4.0/. 
and promotes tumor formation in vivo. Upregulation of $C I P 2 A$ expression is seen in patients with head and neck squamous-cell carcinoma, gastric cancer, breast cancer, or colon cancer, and is associated with aggressive tumor behavior $[13,14]$.

Our aim in this study was to investigate $C I P 2 A$ gene expression in Egyptian AML patients and to determine its effect on treatment response and survival.

\section{Methods}

The present study was conducted at Medical Oncology Department, National Cancer Institute (NCI), Cairo University, Cairo, Egypt. Ethical approval was obtained from the NCI Institutional Review Board, and written informed consent was obtained from all participants.

The study population comprised 60 adult consecutive patients aged 18-65 years with newly diagnosed AML over a period of 1 year. In addition, 22 age- and gendermatched healthy individuals who were donors for bonemarrow transplantation were included as a control group.

Diagnosis of AML was established after clinical, morphological, cytochemical, flow-cytometric, and cytogenetic analyses. All cases met the AML diagnostic standards including involvement of more than $20 \%$ of the blood and/or bone marrow by leukemic myeloblasts.

\section{Clinical end points}

$\mathrm{CR}$ was defined by the following criteria: $<5 \%$ bonemarrow blasts; the absence of blasts with Auer rods; the absence of extramedullary disease; absolute neutrophil count $>1.0 \times 10^{\wedge} 9 / \mathrm{L}$; platelet count $>100 \times 10^{\wedge} 9 / \mathrm{L}$; and independence from red blood cell transfusions. Treatment failure was defined as either resistant disease or relapse. Resistant disease was defined as the failure to achieve CR following completion of initial treatment, with evidence of persistent leukemia in examinations of blood and/or bone marrow. Relapse was defined as $\geq 5 \%$ bone-marrow blasts, reappearance of blasts in the blood, or development of extramedullary disease.

Overall survival (OS) was defined as the time from diagnosis to death from any cause. Data from patients who were alive on the date of the last follow-up were censored on that date. Progression-free survival (PFS) was defined as the time from the initiation of therapy until documented progression or death. For patients without disease progression at the time of analysis, data were rightcensored at the date of their last follow-up [15].

\section{Sample collection, RNA extraction, and CDNA synthesis}

Bone-marrow samples $(1 \mathrm{~mL})$ from patients with AML were collected in a solution containing ethylenediaminetetraacetic acid and treated with erythrocyte-lysis solution. Leukocytes $\left(1 \times 10^{\wedge} 7\right)$ were collected and stored in RLT buffer at $-80{ }^{\circ} \mathrm{C}$ prior to RNA extraction. Total
RNA was extracted using the QIAamp RNA extraction blood mini kit (QIAGEN ${ }^{\circledR}$ Austin, TX, USA, catalog no. 52304), following the manufacturer's instructions. The amount of RNA was measured with a nanodrop spectrophotometer at $260 \mathrm{~nm}$ and $280 \mathrm{~nm}$. A ratio of 1.8-2.0:1 indicated good RNA purity. Subsequently, $1.0 \mu \mathrm{g}$ of RNA was reverse transcribed into cDNA in a $20 \mu \mathrm{L}$ reaction with random primers and a high-capacity cDNA reverse transcription kit (Applied Biosystems, Foster City, CA, USA, catalog no. 4368814) according to the manufacturer's instructions. cDNA was stored at -20 ${ }^{\circ} \mathrm{C}$ until required.

\section{Molecular detection of CIP2A expression}

Quantitative assessment of gene expression levels was performed with the TaqMan Universal PCR Master Mix with no UNG (Applied Biosystems, Foster City, CA. P/N 4440043) as recommended by the manufacturer. The StepOne Real-Time PCR system (Applied Biosystems) was used for real-time analysis. The relative expression levels of the CIP2A gene were analyzed by the comparative CT method $\left(2^{-\Delta \Delta C t}\right)$ [16], with glyceraldehyde-3phosphate dehydrogenase (GAPDH) as the endogenous control. Data are expressed as the fold change in CIP2A gene expression in patients with AML and normalized to the expression levels of the endogenous control and relative to the healthy controls. Median CIP2A expression in the control group was 28 . This value was taken as the cut-off value. Patients with values above median expression were considered to have high expression of $C I P 2 A$, and patients with values below median expression were considered to have low expression of $C I P 2 A$.

\section{Statistical methods}

Data were analyzed with SPSS version 20. Categorical data are summarized as frequencies and percentages. Continuous numerical data are summarized as mean \pm standard deviation (SD), or median and range. Chisquare test was used to compare categorical data and $t$ test or Mann-Whitney $U$ test were used to compare continues data.

OS and PFS were estimated by Kaplan-Meier analysis. The log-rank test was used for comparison of survival curves. All tests were conducted at the 0.05 alpha level, with $95 \%$ confidence intervals $(\mathrm{CI})$.

\section{Results}

In this case-control study, we enrolled 60 patients with AML into the study group and 22 healthy bone-marrow donors into the control group. The baseline demographic and laboratory characteristics of participants are summarized in Table 1. 
Table 1 Clinical and laboratory characteristics of 60 adults with acute myeloid leukemia

\begin{tabular}{|c|c|}
\hline Parameter & Value (mean \pm SD) or distribution ( $(n(\%))$ \\
\hline Age (years) & $36.8 \pm 1.6$ \\
\hline \multicolumn{2}{|l|}{ Gender } \\
\hline Male & $27(45.0)$ \\
\hline Female & $33(55.0)$ \\
\hline Hepatomegaly & $25(41.6)$ \\
\hline Splenomegaly & $23(38.3)$ \\
\hline Lymphadenopathy & $12(20.0)$ \\
\hline Total leukocytic count $\left(\times 10^{9} / \mathrm{L}\right)$ & $49.8 \pm 7.6$ \\
\hline Hemoglobin (g/dL) & $8.1 \pm 0.2$ \\
\hline Platelets $\left(\times 10^{9} / \mathrm{L}\right)$ & $56.7 \pm 9.8$ \\
\hline Peripheral-blood blasts (\%) & $50.4 \pm 26.4$ \\
\hline Bone-marrow blasts (\%) & $62.3 \pm 20.7$ \\
\hline \multicolumn{2}{|l|}{ Bone-marrow cellularity ${ }^{a}$} \\
\hline Normocellular & $9(15.0)$ \\
\hline Hypercellular & $51(85.0)$ \\
\hline \multicolumn{2}{|c|}{ Cytogenetics and molecular classification } \\
\hline Normal karyotype & $9(15.0)$ \\
\hline$t(5: 17)$ & $6(10.0)$ \\
\hline$t(8 ; 21)$ & $6(10.0)$ \\
\hline$t(9 ; 12)$ & $5(8.3)$ \\
\hline Trisomy 21 & $2(3.3)$ \\
\hline Inversion 16 & $1(1.7)$ \\
\hline Trisomy 3 & $1(1.7)$ \\
\hline Multiple & $9(15.0)$ \\
\hline Cytogenetics not performed & $21(35.0)$ \\
\hline \multicolumn{2}{|l|}{ FLT3 status } \\
\hline Wild type & $51(85.0)$ \\
\hline Mutant & $9(15.0)$ \\
\hline \multicolumn{2}{|c|}{ French-American-British classification } \\
\hline M1 & $7(11.7)$ \\
\hline M2 & $20(33.3)$ \\
\hline M3 & $5(8.3)$ \\
\hline M4 & $14(23.3)$ \\
\hline M5a & $4(6.7)$ \\
\hline M7 & $1(1.7)$ \\
\hline \multicolumn{2}{|l|}{ CD34 status } \\
\hline Positive & $35(58.3)$ \\
\hline Negative & $25(41.6)$ \\
\hline
\end{tabular}

${ }^{a}$ Cellularity is the volume ratio of hematopoiesis and fat. Normal of an adult 30 to $70 \%$ and hypercellular over $70 \%$

To define high expression of CIP2A a cut-off value of 28 was taken, which corresponds to the median value of $C I P 2 A$ expression in the control group.

$C I P 2 A$ was over-expressed in 21 patients with AML (35\%), and under-expressed in 39 patients (65\%). The proportions with over-expression and under-expression of $C I P 2 A$ did not significantly differ between the study and control groups $(P=0.31)$. No significant relations were found between $C I P 2 A$ expression and the clinical characteristics (Table 2).

In patients with high-CIP2A expression levels, 13 patients (61.9\%) achieved CR and 8 patients (38.1\%) were 
Table 2 Association between CIP2A expression in patients with acute myeloid leukemia and demographic characteristics, clinical and laboratory data, and risk stratification

\begin{tabular}{|c|c|c|c|}
\hline \multirow[t]{2}{*}{ Parameter } & \multicolumn{2}{|l|}{ CIP2A expression } & \multirow[t]{2}{*}{$P$ value } \\
\hline & High $(n=21)$ & Low $(n=39)$ & \\
\hline & $\begin{array}{l}\text { Value (mean } \pm \text { SD) or distribution } \\
(n(\%))\end{array}$ & $\begin{array}{l}\text { Value (mean } \pm \text { SD) or distribution } \\
(n(\%))\end{array}$ & \\
\hline Age (years) & $33.8 \pm 2.7$ & $38.5 \pm 2.0$ & 0.17 \\
\hline Gender & & & 0.83 \\
\hline Male & $9(33.3)$ & $18(66.7)$ & \\
\hline Female & $12(36.3)$ & $21(63.7)$ & \\
\hline Hepatomegaly & $7(28.0)$ & $18(72.0)$ & 0.28 \\
\hline Splenomegaly & $5(21.7)$ & $18(78.2)$ & 0.11 \\
\hline Lymphadenopathy & $1(8.3)$ & $11(91.6)$ & 0.04 \\
\hline Total leukocyte count $\left(\times 10^{9} / \mathrm{L}\right)$ & $41.6 \pm 10.6$ & $54.3 \pm 10.2$ & 0.43 \\
\hline Hemoglobin (g/dL) & $8.2 \pm 0.4$ & $8.0 \pm 0.3$ & 0.81 \\
\hline Platelets $\left(\times 10^{9} / \mathrm{L}\right)$ & $45.5 \pm 9.6$ & $62.8 \pm 14.3$ & 0.41 \\
\hline Peripheral-blood blasts & $45.8 \pm 5.6$ & $47.9 \pm 4.5$ & 0.78 \\
\hline Bone-marrow blasts & $58.7 \pm 4.3$ & $61.7 \pm 3.6$ & 0.61 \\
\hline FLT3 & & & 0.38 \\
\hline Wild type & $19(90.5)$ & $32(82.1)$ & \\
\hline Mutant & $2(9.5)$ & $7(17.9)$ & \\
\hline Risk stratification & & & 0.94 \\
\hline Favorable & $5(23.8)$ & $9(23.1)$ & \\
\hline Intermediate & $3(14.3)$ & $8(20.5)$ & \\
\hline Poor & $5(23.8)$ & $9(23.1)$ & \\
\hline Not performed & $8(38.1)$ & $13(33.3)$ & \\
\hline
\end{tabular}

resistant to therapy. In patients with low-CIP $2 A$ expression, 27 patients (69.2\%) achieved CR and 12 (30.8\%) were resistant with no statistically significant differences between subgroups. Also, no statistically significant difference was observed in relapse rates between patients with high- and low-CIP $2 A$ expression $(\mathrm{RR}=0.46 ; 95 \%$ CI 0.11-1.99) (Table 3).

The median duration of follow-up was 21.9 months (24.0-27.3 months). There was no statistically significant difference in the estimated PFS between patients with highand low-CIP2A expression $(P=0.28)$ (Fig. 1$)$. OS showed a trend towards longer survival in patients with low-CIP $2 A$ expression. The median OS for all patients with AML was 15.6 months (95\% CI 10.71-20.48 months). The median OS for patients with low-CIP2A expression was 16.0 months (95\% CI 9.0-23.2 months), and that for patients with high-CIP2A expression was 9.67 months (95\% CI 5.114.3 months), although this difference did not reach statistical significance $(P=0.059)$ (Fig. 2).

\section{Discussion}

$P P 2 A$ inhibition is a common event in AML. Restoration of $P P 2 A$ activity induces both arrest of cell growth and caspase-dependent apoptosis, suggesting that $P P 2 A$ inactivation has an important role in AML and can be a promising therapeutic target in hematological malignancies [17].

$C I P 2 A$ is an endogenous $P P 2 A$ inhibitor that interacts directly with the oncogenic transcription factor $c-M y c$, inhibiting PP2A-mediated dephosphorylation of $c-M y c$ and preventing its proteolytic degradation, resulting in $c$ $M y c$ stabilization, promotion of cell growth, and tumor formation [18]. CIP2A is expressed in few normal tissues, but it is overexpressed in many human cancers, and is associated with clinically aggressive cancer behavior. CIP $2 A$ is known to be overexpressed in head and neck squamous-cell carcinoma, breast cancer, colon cancer, and gastric cancer [14].

To date, CIP2A expression levels in patients with AML have been investigated in two studies. In a study involving Asian patients with AML, conventional RTPCR identified higher expression levels (77.14\%) of CIP2A in newly diagnosed AML patients as well as in patients with relapsed AML (70.86\%) compared to $6.25 \%$ in AML patients in $\mathrm{CR}$ and $2.86 \%$ in healthy controls. This finding points to a relation between $C I P 2 A$ overexpression and disease activity in AML [18]. 
Table 3 Association between CIP2A expression in patients with acute myeloid leukemia and the response to induction therapy and the relapse rate

\begin{tabular}{|c|c|c|c|c|}
\hline & $\begin{array}{l}\text { High CIP2A }(n=21) \\
\text { Distribution }[n(\%)]\end{array}$ & $\begin{array}{l}\text { Low CIP2A }(n=39) \\
\text { Distribution }[n(\%)]\end{array}$ & $P$ value & Relative risk $(95 \% \mathrm{Cl})$ \\
\hline Response to induction therapy & & & 0.57 & $1.2(0.6-2.54)$ \\
\hline Complete remission & $13(61.9)$ & $27(69.2)$ & & \\
\hline Resistance & $8(38.1)$ & $12(30.8)$ & & \\
\hline Relapse & & & 0.27 & $0.4(0.11-1.99)$ \\
\hline Still in complete remission & $19(90.5)$ & $31(79.8)$ & & \\
\hline Relapsed & $2(9.5)$ & $8(20.2)$ & & \\
\hline
\end{tabular}

In a cohort of 203 European patients diagnosed with a normal karyotype AML, qRT-PCR was done to find out the prevalence of $C I P 2 A$ in patients with NK-AML. In that study, the median expression of CIP2A was 0.005 (range 0.0027-0.007) in the control group and 0.004 (range 0.00012-0.59) in the AML group. The authors chose a cut-off value of 0.0072 to define high-CIP $2 A$ expression which corresponds to the mean value in the control [9].

In this study, qRT-PCR was used to detect the expression of CIP2A in de novo AML patients. The median expression in the control group which we used as a cut-off was much higher than the value reported by Barragan et al. [9].

Based on this cut-off value, we found that $35 \%$ of the patients had a high-CIP2A level; a value higher than that reported by Barragan et al. [9], and much less than that reported by Wang et al. [18] who used conventional RTPCR. This may be explained by the fact that the relative quantitation method and the threshold for determining high and low expression in our study were different from those used by the other two studies.

In the current study, no significant relations was found between CIP2A expression and the clinical and laboratory data; a finding consistent with previous findings [9]. Similarly, we found that the level of expression of CIP2A did not have a significant effect on the response to induction chemotherapy or relapse rate $(P=0.57$ and $P=0.27$, respectively), which is in line with previous findings [9].

Noteworthy, we found a trend towards improved survival in patients with low-CIP2A expression with a 3year survival probability of $36 \%$ and $25 \%$ for patients

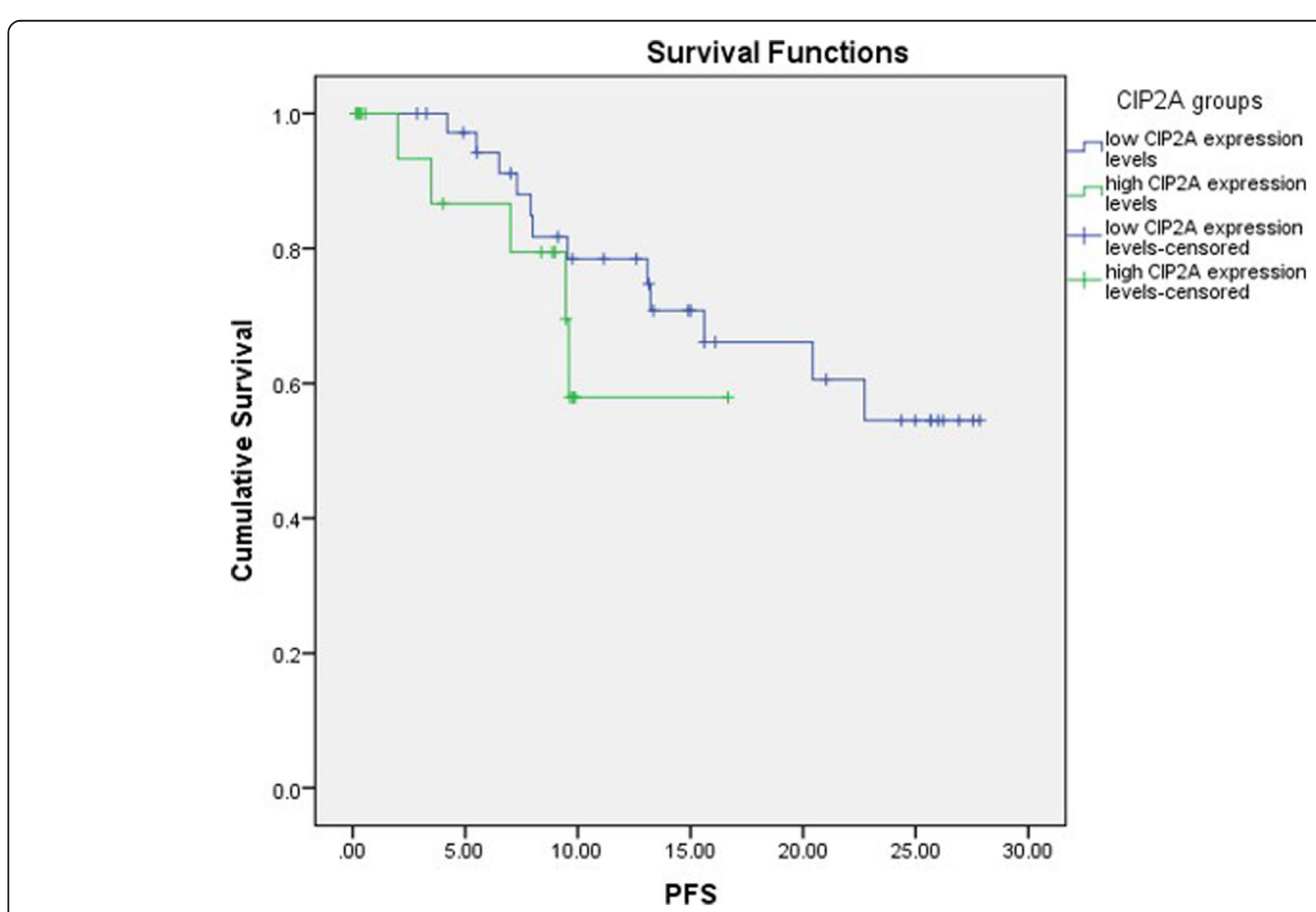

Fig. 1 Progression-free survival in patients with acute myeloid leukemia and high or low levels of CIP2A expression 


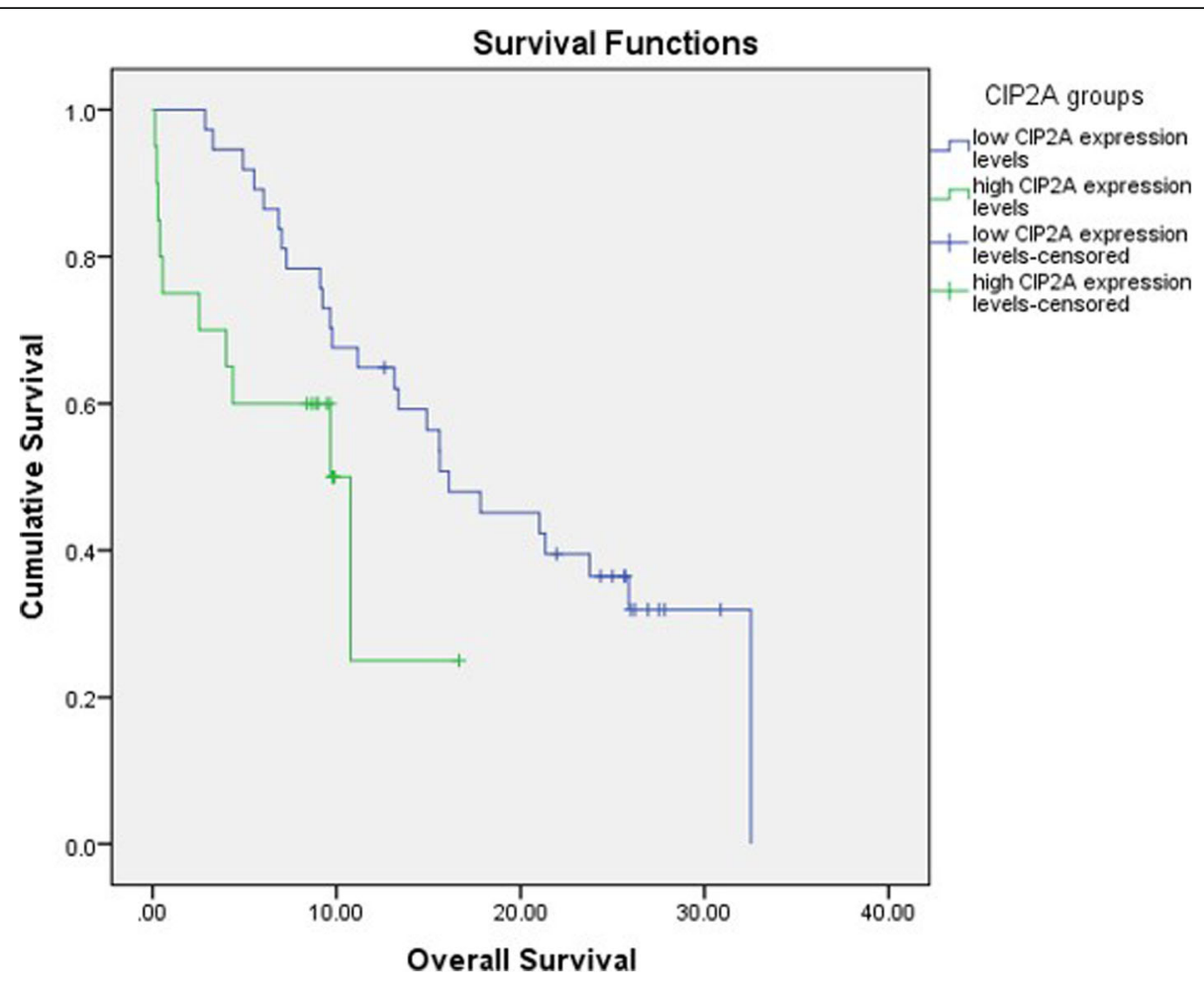

Fig. 2 Overall survival in patients with acute myeloid leukemia and high or low levels of CIP2A expression

with low- and high-CIP $2 A$ expression, respectively. Barragan et al. [9] reported a close percentage (27\%) in patients with high $C I P 2 A$, but a much higher percentage (50\%) in patients with low expression.

At 3 years, the current study recognized relapse in $54.5 \%$ and $57.9 \%$ of patients with low- and high-CIP $2 A$ expression, respectively. These values are higher than those reported by Barragan et al. [9] (30\% and 47\% for low- and high-CIP $2 A$ expression)

The lower PFS and OS reported in this study compared to those reported by Barragan et al. [9] may be attributed to the fact that the European trial was larger and only patients with NK-AML were allowed to participate.

\section{Conclusion}

High-CIP2A expression was associated with a trend towards shorter OS in adult Egyptian AML patients. It might serve as a marker to predict poor prognosis. However, larger studies are needed to determine the most suitable cut-off for defining high versus low CIP2A level and its impact on response to induction chemotherapy as well as its effect on PFS and OS.

\section{Abbreviations}

AML: Acute myeloid leukemia; Cl: Confidence intervals; CIP2A: Cancerous inhibitor of protein phosphatase 2A; CN-AML: Cytogenetically normal AML; CR: Complete remission; GAPDH: Glyceraldehyde-3-phosphate dehydrogenase; OS: Overall survival; PCR: Polymerase chain reaction; PFS: Progression-free survival; PP2A: Protein phosphatase 2A; RR: Relative risk

\section{Acknowledgements \\ Not applicable}

\section{Authors' contributions}

Conception and design: R.S, A.I, and F.S. Data acquisition, analysis, and interpretation: N.H, H.E.S, and H.A.S. Drafting: N.H, H.E.S, and H.A.S. Critical revision: R.S, A.I, and F.S. Final approval: all authors. Agreement to be accountable for all aspects of the work: All authors. All authors read and approved the final manuscript.

\section{Funding}

This research did not receive any specific grant from funding agencies in the public, commercial, or not-for-profit sectors.

\section{Availability of data and materials}

The datasets used and analyzed during the current study are available from the corresponding author on reasonable request.

\section{Ethics approval and consent to participate}

Ethical approval was obtained from the National Cancer Institute Institutional Review Board, and written informed consent was obtained from all study participants. Ethical committee approval no.: I-21101h (Ethical committee of Clinical and Chemical Pathology Department, Cairo University Faculty of Medicine).

\section{Consent for publication}

Not applicable

\section{Competing interests}

The authors declare that they have no competing interests.

\section{Author details}

${ }^{1}$ Clinical Pathology Department, National Cancer Institute (NCI), Cairo University, Cairo, Egypt. ${ }^{2}$ Clinical Pathology Department, Cairo University, 
Cairo, Egypt. ${ }^{3}$ Medical Oncology Department, National Cancer Institute (NCl), Cairo University, Cairo, Egypt.

Received: 19 February 2020 Accepted: 16 June 2020

Published online: 03 August 2020

\section{References}

1. Kuykendall A, Duployez N, Boissel N et al (2018) Acute myeloid leukemia: the good, the bad, and the ugly. Am Soc Clin Oncol Educ Book 38:555-573

2. Mudgapalli N, Nallasamy P, Chava $\mathrm{H}$ et al (2019) The role of exosomes and MYC in therapy resistance of acute myeloid leukemia: challenges and opportunities. Mol Asp Med 70:21-32

3. Grimwade D, Walker H, Harrison G et al (2001) The predictive value of hierarchical cytogenetic classification in older adults with acute myeloid leukemia (AML): analysis of 1065 patients entered into the United Kingdom Medical Research Council AML11 trial. Blood. 98(5):1312-1320

4. Byrd JC, Mrozek K, Dodge RK et al (2002) Pretreatment cytogenetic abnormalities are predictive of induction success, cumulative incidence of relapse, and overall survival in adult patients with de novo acute myeloid leukemia: results from cancer and leukemia group B (CALGB 8461). Blood. 100(13):4325-4336

5. Schichman SA, Caligiuri MA, Strout MP et al (1994) ALL-1 tandem duplication in acute myeloid leukemia with a normal karyotype involves homologous recombination between Alu elements. Cancer Res 54(16): 4277-4280

6. Nakao M, Yokota S, Iwai T et al (1996) Internal tandem duplication of the flt3 gene found in acute myeloid leukemia. Leukemia. 10(12):1911-1918

7. Tanner SM, Austin JL, Leone $\mathrm{G}$ et al (2001) BAALC, the human member of a novel mammalian neuroectoderm gene lineage, is implicated in hematopoiesis and acute leukemia. Proc Natl Acad Sci U S A 98(24):1390113906

8. Bullinger L, Dohner K, Bair E et al (2004) Use of gene-expression profiling to identify prognostic subclasses in adult acute myeloid leukemia. N Engl J Med 350(16):1605-1616

9. Barragan E, Chillon MC, Castello-Cros R et al (2015) CIP2A high expression is a poor prognostic factor in normal karyotype acute myeloid leukemia. Haematologica. 100(5):e183-e185

10. Pippa $R$, Odero MD (2020) The role of MYC and PP2A in the initiation and progression of myeloid Leukemias. Cells 9(3):544

11. Ramaswamy K, Spitzer B, Kentsis A (2015) Therapeutic re-activation of protein phosphatase 2A in acute myeloid leukemia. Front Oncol 5:16

12. Ruvolo PP (2015) The interplay between PP2A and microRNAs in leukemia. Front Oncol 5:43

13. Lesaffre $E$ (2008) Use and misuse of the p-value. Bull NYU Hosp Jt Dis 66(2): 146-149

14. Come C, Laine A, Chanrion M et al (2009) CIP2A is associated with human breast cancer aggressivity. Clin Cancer Res 15(16):5092-5100

15. Cheson BD, Bennett JM, Kopecky KJ et al (2003) Revised recommendations of the international working group for diagnosis, standardization of response criteria, treatment outcomes, and reporting standards for therapeutic trials in acute myeloid leukemia. J Clin Oncol 21(24):4642-4649

16. Livak KJ, Schmittgen TD (2001) Analysis of relative gene expression data using real-time quantitative PCR and the 2(-Delta Delta C(T)) method. Methods. 25(4):402-408

17. Cristobal I, Garcia-Orti L, Cirauqui $C$ et al (2011) PP2A impaired activity is a common event in acute myeloid leukemia and its activation by forskolin has a potent anti-leukemic effect. Leukemia. 25(4):606-614

18. Wang J, Li W, Li L et al (2011) CIP2A is over-expressed in acute myeloid leukaemia and associated with HL60 cells proliferation and differentiation. Int J Lab Hematol 33(3):290-298

\section{Publisher's Note}

Springer Nature remains neutral with regard to jurisdictional claims in published maps and institutional affiliations.

\section{Submit your manuscript to a SpringerOpen ${ }^{\circ}$ journal and benefit from:}

- Convenient online submission

- Rigorous peer review

- Open access: articles freely available online

- High visibility within the field

- Retaining the copyright to your article

Submit your next manuscript at $\boldsymbol{\nabla}$ springeropen.com 